\title{
“VOCÊ CORTA UM VERSO, EU INVENTO OUTRO": O PODER LINGUÍSTICO-DISCURSIVO DA MÚSICA DE PROTESTO NO
}

\author{
PERÍODO DA DITADURA MILITAR
}

\author{
Maria Aparecida Rocha Gouvêa ${ }^{1}$
}

\begin{abstract}
Resumo: No período da ditadura militar no Brasil, a arte, especialmente a música, assumiu postura de oposição ao regime militar. Para isso, os compositores tinham de utilizar princípios e recursos linguísticos e discursivos que persuadissem o público subliminarmente, já que as manifestações explícitas eram alvos da censura. Este artigo objetiva analisar as estratégias utilizadas nas canções, identificando as marcas discursivas que colaboravam para persuadir o público e marcar posição de oposição ao regime. Trata-se de uma pesquisa bibliográfica, com análise de trechos das canções da época. Para isso, utilizaremos pressupostos teóricos históricos, culturais e linguístico-discursivos, principalmente da Análise do Discurso Francesa de Maingueneau e Charaudeau. Concluímos que muitas estratégias foram utilizadas, de forma a construir ethe de resistência ao regime militar.
\end{abstract}

Palavras-chave: ditadura militar; discurso; música de protesto.

\begin{abstract}
During the military dictatorship in Brazil, arts, especially the music, often had a message opposed to that of the military regime. To engender opposition to such regime, composers had to use linguistic, discursive and stylistic resources that subliminally persuade the public, since explicit manifestations against the regime were targets of censorship. This works aims to analyze the strategies used in the songs, tries to identify the discursive marks and persuasive strategies used and show the opposition against the regime. The research is based on a literature review, with analysis of parts of songs from that time period. In this study, historical, cultural and linguistic-discursive principles were considered, especially the ones offered by the French Approach to Discourse Analysis of Maingueneau and Charaudeau. The research concludes that many strategies have been used, with the goal of build ethe of resistance to the military regime.
\end{abstract}

Keywords: military dictatorship; discourse; protest music

${ }_{1}$ Professora do Centro Universitário de Volta Redonda - UniFOA. E-mail: cidarochagouvea@hotmail.com 


\section{INTRODUÇÃO}

Nos chamados Anos de Chumbo, o Brasil viveu um dos seus períodos históricos mais difíceis. O regime militar se instalou no país e aqui permaneceu por vinte e um anos. Preocupados em respaldar suas ações, os militares trataram de criar e registrar em documentos o que garantiria a legalidade de seus atos, como afirma Quadrad (2006, p. 130).

Logo nos primeiros dias da ditadura militar, uma das principais características do novo governo começou a ser esboçada. A ditadura brasileira foi obsessivamente preocupada com a formação de um arcabouço legal e jurídico que lhe desse respaldo e legitimidade. A edição dos Atos Institucionais ao longo de praticamente todo o período ditatorial é um claro exemplo dessa obsessão. No Brasil ditatorial fazia-se lei para tudo.

Tal atitude possibilitou que o regime militar instaurasse no país um clima de terror e medo. Entretanto, uma parcela da população, formada, principalmente, por intelectuais, artistas, políticos da esquerda, ativistas de movimentos sindicais, professores e estudantes, entre outros, marcaram posição de combate ao regime.

Em reação, os militares perseguiam os opositores, incluindo em suas práticas prisões, torturas e exílios forçados e também censura aos meios de comunicação e à arte.

No meio artístico, peças de teatro, filmes, músicas e livros foram mutilados parcial ou integralmente, fazendo com que, sem condições de produção, renomados artistas e intelectuais optassem pelo exílio. Alguns foram expulsos do país.

Em especial, a música popular brasileira - MPB teve importante papel de repúdio ao regime ditatorial. Muitos compositores surgiram nesse período, principalmente nos grandes festivais de música, com plateias que lotavam os auditórios, ansiando por canções com mensagens políticas.

Este artigo pretende analisar as estratégias utilizadas pelos compositores nas canções e as marcas discursivas que colaboravam para persuadir o público. Analisaremos também os recursos linguístico-discursivos que serviam de elemento de proteção de face dos comi positores, responsáveis pela construção dos ethe discursivos desses artistas.

\section{A ARTE DE PROTESTO}

De modo geral, a realidade social desse período mudou o rumo da arte brasileira. Devido à repressão imposta pelos militares, o discurso artístico se transformou, utilizando mensagens subliminares que possibilitavam a divulgação das obras e, ao mesmo tempo, protegiam os artistas contra a violência promovida pelo regime.

Segundo Stephanou (2001, p. 300), nesse período,

a arte seria o lugar onde teria início a reação ao Regime Militar, o início de uma resistência de fato. (...) O cinema era uma forma de fazer política; o teatro, de 
resistir; a música, de convocar para a luta, a imprensa, de denunciar. A reação cultural ao Movimento Militar foi marcada por uma arte conscientizadora, mobilizadora, de discurso revolucionário. A cultura apontou na direção da resistência ao Regime, e para isso, se equiparou ao inimigo, se militarizando, no seu pensamento, na sua estética, no seu vocabulário, nos seus objetivos.

Anteriormente ao golpe, o teatro já denunciava a realidade social, mas após 64, isso foi ampliado. Antes dos espetáculos, frequentemente, os movimentos sociais davam avisos ou convocavam o público para manifestações. Nesse período, foram destaque o Show Opinião (1964), peça redigida coletivamente, mesclando textos e músicas; a peça Arena Conta Zumbi (1966), de Augusto Boal e Gianfrancesco Guarnieri; e Roda Viva (1968), de Chico Buarque, alvo da repressão militar, quando o Comando de Caça aos Comunistas (CCC) invadiu o teatro, destruiu o cenário, espancou e humilhou os atores da peça.

O cinema também foi de grande destaque para a arte do período. Podemos citar o Cinema Verdade, que era composto por documentários que mostravam a realidade do país, sem efeitos especiais e o Cinema Novo que possibilitava debates profundos, influenciando o contexto histórico, com temáticas como o anti-imperalismo, o anticapitalismo, a denúncia do subdesenvolvimento e a defesa da justiça social e do nacionalismo. Nesse período, muitos filmes foram lançados, como Deus e o Diabo na Terra do Sol (1964), Terra em Transe (1967) e O Bandido da Luz Vermelha (1968), entre outros.

$\mathrm{Na}$ literatura, muitos livros de denúncia foram lançados no período, com destaque para os ensaios acadêmicos, a poesia engajada, os livros eróticos e também livros ficcionais, como Quarup (1967), de Antônio Callado. Segundo Stephanou (2001, p. 189) "Quarup foi o livro de maior impacto de período e um dos mais lidos, apesar de suas mais de 500 páginas", esgotando três edições em quatro meses.

As artes plásticas também marcaram posição contra o regime, com seus happenings. Merece destaque também o grupo que criou a Rex Gallery, em São Paulo, em 1966: Wesley Duke Lee, Nélson Leirner e Geraldo de Barros. Os artistas montaram um local de acontecimentos que funcionou durante um ano.

Muitos teóricos incluem a imprensa como forma de arte nesse período. A imprensa combativa abarcava grandes intelectuais, como Carlos Heitor Cony, Darcy Ribeiro, Affonso Romano de Sant'Anna, Ferreira Gullar, Thiago de Mello, entre outros. Merecem destaque a Revista Civilização Brasileira e os jornais Correio da Manhã e Pasquim, alvo de censura, depredações e bombas.

A música, objeto de análise deste artigo, foi um importante veículo de oposição ao regime. Através de metáforas, jogos de palavras, estratégias de persuasão, os compositores marcaram presença contra os militares. Os grandes festivais de música eram o ponto de encontro da juventude universitária que clamava por mensagens políticas nas canções e quando isso não acontecia, a vaia era a resposta de desagrado. Muitos compositores e intérpretes, como Chico Buarque, Geraldo Vandré, Caetano Veloso, Gilberto Gil, entre outros, foram censurados e perseguidos pelos militares e, por isso, perceberam a necessidade de utilizar estratégias que possibilitassem a veiculação das mensagens almejadas pelo público. Diversas canções do período, até hoje, são lembradas como símbolo de resistência como, 
por exemplo, Disparada, de Geraldo Vandré e Théo de Barros; Apesar de você, de Chico Buarque; Cálice, de Chico Buarque e Gilberto Gil e Pra não dizer que não falei de flores, de Geraldo Vandré.

\section{CANÇÕES DE PROTESTO E ESTRATÉGIAS UTILIZADAS PELOS COMPOSITORES}

Podemos, certamente, afirmar que, no campo artístico, a canção de protesto foi um dos gêneros que mais colaborou para a contestação das ações militares, principalmente através dos festivais de música, que, por serem veiculados pela televisão, alcançavam o público em casa. O forte valor persuasivo das canções propiciava determinada vantagem diante dos outros gêneros artísticos. Além disso, a música popular brasileira vivia um momento propício nesse período, com programas de música diários na televisão: O Fino da Bossa, Bossaudade, Jovem Guarda, entre outros.

É importante ressaltar também que, quando se analisa canções, é necessário considerar que esse gênero é composto de letra e melodia e que ambas colaboram para a construção de sentido do texto.

Sobre isso, Valverde (2008, p. 272) ressalta que

a canção não se reduz ao feliz casamento entre palavra e música: a voz, pela singularidade de seu timbre, torna presente o corpo e o desempenho de alguém real; a melodia, a seu modo e sem dizer nada, conta uma história envolvente, quando não arrebatadora; o arranjo e a instrumentalização datam e localizam o acontecimento que se canta, conferindo concretude e familiaridade à ficção; as palavras, enfim, formam o elo simbólico de uma comunidade de falantes que são anônimos e se desconhecem, mas se reconhecem, enquanto falantes. Cada um desses aspectos contribui para envolver e aproximar misteriosamente os ouvintes, através da mediação proporcionada pela performance do cantor.

Como exemplo, podemos citar a canção Domingo no Parque, de Gilberto Gil. É possível observar que a melodia acompanha a estrutura do enredo, possibilitando a criação de um clima de suspense, necessário à trama narrativa. No clímax, o ritmo da canção assume mais velocidade e agressividade e, ao final, fica mais lento para encerrar a narrativa.

$$
\begin{gathered}
\text { Domingo no parque - Gilberto Gil - } 1967 \\
{[\ldots]} \\
\text { O sorvete é morango - é vermelho } \\
\text { Oi, girando, e a rosa - é vermelha } \\
\text { Oi, girando, girando - é vermelha } \\
\text { Oi, girando, girando - olha a faca! }
\end{gathered}
$$

$$
\begin{gathered}
\text { Olha o sangue na mão - ê, José } \\
\text { Juliana no chão - ê, José }
\end{gathered}
$$


Outro corpo caído - ê, José

Seu amigo, João - ê, José

Amanhã não tem feira - ê, José

Não tem mais construção - ê, João

Não tem mais brincadeira - ê, José

Não tem mais confusão - ê, João

Durante o período militar, os compositores utilizaram várias estratégias persuasivas para se esquivarem dos questionamentos e intervenções da censura, principalmente após a apresentação de Geraldo Vandré no III Festival Internacional da Canção, em 1968, quando foi instaurada a censura prévia às canções. Essas estratégias colaboraram para a construção de um ethos de oposição ao regime, mas, ao mesmo tempo, funcionavam como recurso de proteção de face para o compositor. O termo proteção de face é utilizado na Análise do Discurso francesa de Maingueneau e Charaudeau.

Maingueneau (2008, p. 38) registra que cada indivíduo possui duas faces em uma situação de comunicação. Portanto, como cada ato comunicativo pressupõe, no mínimo, dois participantes, há quatro faces envolvidas na comunicação: a face positiva e a face negativa de cada um dos interlocutores, sendo que face negativa corresponde ao território de cada um (seu corpo, sua intimidade etc.) e a face positiva corresponde à "fachada social", ou seja, à imagem que tentamos apresentar aos outros.

Dessa forma, tratar de discurso tendo como contexto histórico o período da ditadura militar pressupõe, certamente, discutir esse termo, já que nesse período havia restrições discursivas e comportamentais impostas pelo regime.

Maingueneau (2008, p. 38) defende ainda que "todo ato de enunciação pode constituir uma ameaça para uma ou várias dessas faces”, o que faz com que o enunciador busque estratégias discursivas para preservar suas faces, sem ameaçar a do seu interlocutor.

No período da ditadura militar, por exemplo, os compositores utilizavam mensagens de repúdio às ações do governo que valorizavam a face positiva perante a plateia, mas com possibilidade de desvalorização perante os militares. Por isso, a mensagem tinha de ser sutil, de forma a dizer o que não podia ser dito.

Sobre o ethos, Amossy (2005, p. 9) afirma que "todo ato de tomar a palavra implica a construção de uma imagem de si” e com a música não foi diferente. Dessa forma, os recursos disponíveis na língua - dêiticos, metáfora, metonímia, ironia, construções dialéticas, intertextualidade, entre outros - possibilitavam a manifestação de repúdio à realidade da época, como também de protegia o enunciador.

Vale ressaltar que, nesse período, os censores não eram pessoas capacitadas para analisar a arte e, por isso, muitas vezes não percebiam ou demoravam a perceber a intenção discursiva do compositor. Muitos censores eram funcionários públicos readaptados ou esposas de militares.

Na perspectiva do ethos, Charaudeau (2006, p. 116) também questiona e expõe sobre o sentido do discurso. 
Como aceitar que a imagem que o sujeito falante faz dele próprio não corresponderia ao que ele é como indivíduo? Aqui está um dos menores paradoxos da comunicação humana: sabemos que todo sujeito que fala pode jogar com máscaras, ocultando o que ele é pelo que diz, e, ao mesmo tempo, o interpretamos como se o que ele dissesse devesse necessariamente coincidir com o que ele é. Há uma espécie de desejo de essencialização, tanto da parte do locutor quanto da do interlocutor, nessa busca de sentido de discurso.

Vejamos, então, algumas estratégias utilizadas pelos compositores:

\title{
Dêiticos
}

Nas análises das canções, percebemos que essa estratégia era muito utilizada pelos compositores. O uso do pronome possibilita uma interlocução imaginária para dizer o que não podia ser dito. Como exemplo, citaremos, três canções que utilizam o pronome você, entretanto marcando distintas interlocuções.

\author{
Apesar de você - Chico Buarque - 1970 \\ Hoje você é quem manda \\ Falou, tá falado \\ Não tem discussão \\ A minha gente hoje anda \\ Falando de lado \\ E olhando pro chão, viu \\ $[\ldots]$
}
Pesadelo - Paulo César Pinheiro e Maurício Tapajós - 1972
[...]
Você corta um verso, eu escrevo outro
Você me prende vivo, eu escapo morto
De repente olha eu de novo
Perturbando a paz, exigindo troco
Vamos por aí eu e meu cachorro
Olha um verso, olha o outro
Olha o velho, olha o moço chegando
Que medo você tem de nós, olha aí

$[\ldots]$

Comportamento geral - Gonzaguinha - 1973

Você deve notar que não tem mais tutu

E dizer que não está preocupado

Você deve lutar pela xepa da feira

E dizer que está recompensado

Você deve estampar sempre um ar de alegria 
E dizer "tudo tem melhorado"

Você deve rezar pelo bem do patrão

E esquecer que está desempregado

$[\ldots]$

Na primeira canção, Chico, uilizando uma disfarçada temática amorosa, se refere ao Presidente Médici; na segunda, os compositores Paulo César Pinheiro e Maurício Tapajós utilizam você para se referirem, com uma provocação explícita, aos censores; e na terceira, Gonzaguinha utiliza o mesmo pronome para se referir ironicamente ao cidadão que assistia a tudo passivamente. Com esse recurso, é possível observar a construção de um ethos atrevido, que diz o que pensa, mas que, para preservar sua face, não identifica explicitamente, o interlocutor.

$\mathrm{Na}$ canção abaixo, os pronomes demonstrativos são utilizados sem referência, possibilitando que cada leitor/ouvinte faça as inferências que desejar.

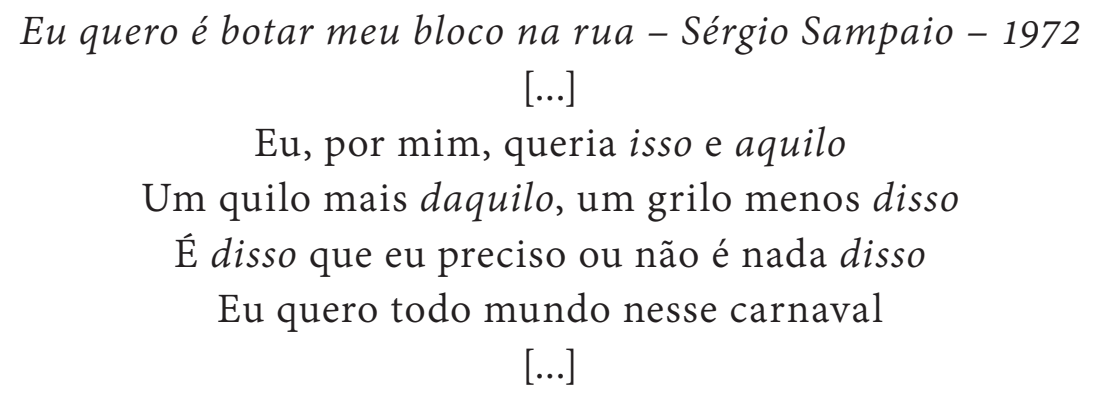

\title{
Metáfora
}

Foi bastante utilizada pelos compositores para transmitir mensagens políticas. Como "envolve termos de domínios conceptuais distintos, entre os quais promove uma assimilação mental” (AZEREDO, 2008, p. 485), a transferência semântica desses termos era essencial para o diálogo entre compositor e plateia, de forma a colaborar significativamente para a persuasão. Vejamos o exemplo de um trecho da canção de Aldir Blanc e João Bosco, $O$ bêbado e a equilibrista.

\author{
O bêbado e a equilibrista - Aldir Blanc e João Bosco - $1976^{2}$ \\ Caía a tarde feito um viaduto \\ E um bêbado trajando luto \\ Me lembrou Carlitos \\ A lua \\ Tal qual a dona do bordel \\ Pedia a cada estrela fria \\ Um brilho de aluguel
}

\footnotetext{
2 Divergências na apresentação do ano de criação da canção: 1976 (Albin, 1998, p. 106) e 1979 (Severiano e Mello, 1998, p. 253). Optamos por Ricardo Cravo Albin (Enciclopédia da Música Popular Brasileira).
} 
E nuvens!

Lá no mata-borrão do céu

Chupavam manchas torturadas

- Que sufoco!

Louco!

$[\ldots]$

- o bêbado $\rightarrow$ o povo oprimido que leva as dificuldades com humor, por isso a associação ao personagem mais popular de Charles Chaplin, o Carlitos;

- a equilibrista $\rightarrow$ a esperança que dança na corda bamba de sombrinha, tentando se equilibrar em um tempo em que tudo colaborava para o desequilíbrio;

- a lua tal qual a dona de um bordel $\rightarrow$ os políticos que defendiam o regime para se promoverem. Eram vulgarmente conhecidos como luas-pretas. A referência ao bordel representa a moeda de troca: favores concedidos a eles;

- cada estrela fria $\rightarrow$ os militares, poderosos sem sentimentos;

- brilho de aluguel $\rightarrow$ ganhos pessoais e eleitorais obtidos pelos civis a favor do regime;

- as nuvens no mata-borrão do céu $\rightarrow$ os torturadores que tratavam de apagar os vestígios de suas ações criminosas;

- o céu $\rightarrow$ o lugar onde estavam os torturadores.

\section{Metonímia}

Foi utilizada como recurso de preservação de face, colaborando para um apagamento do sujeito. Na canção abaixo, Viola Enluarada, de Marcos Valle e Paulo Sérgio Valle, percebemos que a "parte" colabora para a não identificação do "todo", no caso, do enunciador.

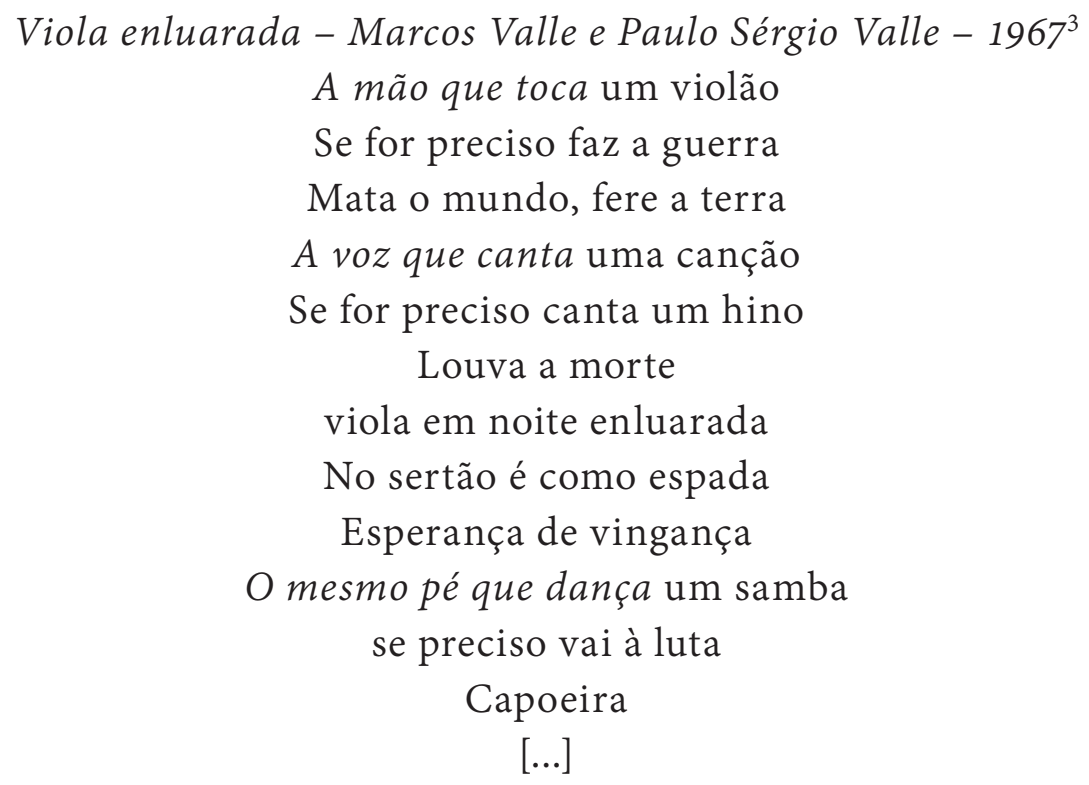

3 Divergências na apresentação do ano de criação da canção: 1967 (Albin, 1998, p. 801) e 1968 (Severiano e Mello, 1998, p. 134). Optamos por Ricardo Cravo Albin (Enciclopédia da Música Popular Brasileira). 


\title{
Ironia
}

Também foi muito utilizada no período. Sabemos que a ironia é um recurso privilegiado que depende da cumplicidade do leitor/ouvinte para ser compreendido. Na canção abaixo, Chico a utiliza para agradecer o mínimo permitido ao cidadão brasileiro: comer, dormir, respirar, sorrir. Vale ressaltar que, a expressão Deus the pague é utilizada como agradecimento a algum favor por alguém que não tem recursos financeiros para pagar ou esteja em situação vulnerável, o que possibilita a construção de um ethos de carência.

\author{
Deus the pague - Chico Buarque - 1971 \\ Por esse pão pra comer, por esse chão pra dormir \\ A certidão pra nascer e a concessão pra sorrir \\ Por me deixar respirar, por me deixar existir \\ Deus lhe pague \\ $[\ldots]$
}

\section{Construções dialéticas}

Nesse período, os compositores utilizavam as construções dialéticas como forma de propor a construção de outra realidade e, dessa forma, propor também a mudança, a transformação, como podemos verificar na canção abaixo, na qual fica subentendida a oposição entre muro e ponte - metáforas com significados relevantes no período. Por meio dessas metáforas, podemos inferir o ethos de cada lado: muro (censor) ponte (compositor). O verso Que medo você tem de nós, olha aí também colabora para a construção de um ethos consciente do poder da palavra.

\section{Pesadelo - Paulo César Pinheiro e Maurício Tapajós - 1972 \\ Quando o muro separa uma ponte une \\ Se a vingança encara o remorso pune \\ Você vem me agarra, alguém vem me solta}

[...]

Que medo você tem de nós, olha aí.

$[\ldots]$

\section{Intertextualidade}

Foi bastante utilizada como álibi no período. Diante dos questionamentos dos censores, os compositores recorriam ao texto original como argumento. Na canção abaixo, denominada Dom Quixote, Arnaldo Batista e Rita Lee parodiam o clássico de Cervantes, ironizando a figura do soldado brasileiro. Chamados a depor, argumentaram que estavam fazendo uma releitura da obra espanhola.

$$
\begin{gathered}
\text { Dom Quixote - Arnaldo Batista e Rita Lee - } 1967 \\
{[\ldots]} \\
\text { Ei, vê que tudo mudou } \\
\text { E a donzela casou }
\end{gathered}
$$




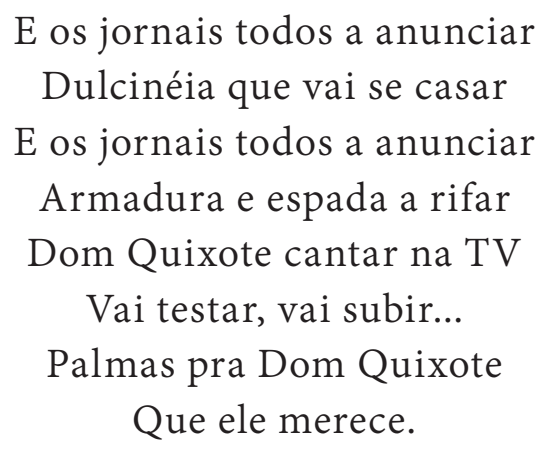

\section{CONCLUSÃO}

Criar em um momento histórico marcado pela ausência de liberdade de expressão é um grande desafio. A partir dessa premissa, podemos concluir que a canção de protesto foi essencialmente persuasiva nesse período, dada sua função social.

O compositor necessitava utilizar recursos linguístico-discursivos que possibilitassem a veiculação das mensagens de maneira implícita e, ao mesmo tempo, preservar sua face. É importante registrar, também, que a compreensão dessas mensagens não era acessível a todas as pessoas e que permitiam outras leituras, em caso de censura ou interrogatório. Assim, o compositor optava por uma ou outra, conforme a conveniência do momento. Nesse período, cada palavra, cada expressão implícita ou explícita era importante para a construção do sentido da canção e continha um valor ideológico.

Para finalizar, deixamos o pensamento de Miranda (2007, p. 470) como ponto para reflexão: "Mais do que um adereço de nossas vidas, a música pode se apresentar como expressão de nexos profundos, bem como interlocutora de um dado tempo e das formas de sociabilidades aí constituídas."

\section{REFERÊNCIAS}

ALBIN, Ricardo Cravo. Enciclopédia da música popular brasileira: popular, erudita e folclórica. São Paulo: Art Editora: Publifolha, 1998.

AMOSSY, Ruth (org.) Imagens de si no discurso: a construção do ethos. São Paulo: Contexto, 2005.

AZEREDO, José Carlos de. Gramática Houaiss da língua portuguesa. São Paulo: Publifolha, 2008.

CHARAUdEAU, Patrick. Discurso político. Trad. Fabiana Komesu e Dilson Ferreira da Cruz. São Paulo: Contexto, 2006.

MaINGUENEAU, Dominique. Análise de textos de comunicação. São Paulo: Cortez, 2008.

MIRANDA, Dilmar Santos de. "Música popular e sociedade brasileira". In: COSTA, Nelson Barros de 
(org.). O charme dessa nação: música popular, discurso e sociedade brasileira. Fortaleza: Expressão Gráfica e Editora, 2007.

QUADRAT, Samantha Viz. “A ditadura civil-militar em tempo de (in)definições.” In: MARTINHO, C. P. (org.). Democracia e ditadura no Brasil. Rio de Janeiro: Eduerj, 2006. p.127-139.

SEVERIANO, Jairo; MELLO, Zuza Homem. A canção no tempo: 85 anos de músicas brasileiras. Vol. 2 . São Paulo: Editora 34, 1998.

STEPHANOU, Alexandre Ayub. Censura no regime militar e militarização das artes. Porto Alegre: EDIPUCRS, 2001, 328 p.

VALVERDE, Monclar. “Mistérios e encantos da canção”. In: MATOS, C. N. de; TRAVASSOS, E.; MEDEIROS, F. T. de. (orgs). Palavra cantada: ensaios sobre poesia, música e voz. Rio de Janeiro: 7 Letras, 2008. p. $268-277$. 